\title{
Synthesis and Electrochemical Evaluation of Some Organic Molecules as an Antioxidant Agents
}

Ngono Thérèse Rosie Lauriane ${ }^{1}$, Jamila Bouali², Rachida Najih ${ }^{1}$, Mostafa Khouili², Abderrafia Hafid ${ }^{2}$ and Abdelilah Chtaini ${ }^{1 *}$

${ }^{1}$ Equipe of Molecular Electrochemistry and Inorganic Materials, Sultan Moulay Slimane University, Faculty of Science and Technology of Beni Mellal, Morocco ${ }^{2}$ Laboratory of Organic and Analytical Chemistry, Faculty of Science and Technology, Beni Mellal, Morocco

\begin{abstract}
A series of new benzamides were synthesized. The chemicals structures were confirmed by elemental analyses ${ }^{1} \mathrm{H}$ NMR and ${ }^{13} \mathrm{C}$ studies. The antioxidant activity of the synthesized compounds was evaluated by square wave voltammetry. A new approach, for antioxidant capacity determination was proposed. It is based on the using of the xanthine-xanthine oxidase system coupled with $\mathrm{H}_{2} \mathrm{O}_{2}$ electrochemical sensor.
\end{abstract}

Keywords: Voltammetry; Antioxidant capacity; Xanthine; Xantine oxidase

\section{Introduction}

Reactive oxygen species (ROS) including superoxide anion $\left(\mathrm{O}_{2}{ }^{-}\right)$ hydrogen peroxide, and hydroxyl radical ( $\mathrm{OH}$.$) , are generated naturally$ in vivo during metabolic processes and keeps in a balance level in normal living organisms [1]. However, when a body is subject to the environmental or behavioral stressors (pollution, sunlight exposure, cigarette smoking, excessive alcohol consumption, etc,), excess ROS are generated [2]. If the excess ROS cannot be scavenged in time, they would attack and induce DNA, proteins and lipids damage, and impede normal cell functions [3]. Therefore, overproduction of ROS is associated with numerous diseases like cancer and Alzheimer's disease, as well as aging. In living systems, the deleterious effects of ROS can be neutralized by the endogenous and exogenous antioxidant systems [4]. Antioxidants are synthetic or natural substances that prevent or delay the oxidative damage by scavenging the free radicals. Fruits and vegetables are good sources of high amounts of known antioxidants.

The aims of this study are to synthesize derivatives of benzamides, from the arylamines and salicylic acid under the action of thionyl chloride, and tested as antioxidants.

The antioxidant capacity was evaluated, by coupling an amperometric sensor for $\mathrm{H}_{2} \mathrm{O}_{2}$ detection, obtained by modification of paste carbon graphite electrode with copper, with xanthine oxidase (XOD) immobilized at silice-xanthine (XA) enzymatic system, as generator of $\mathrm{O}_{2}$. radicals. The advantages of this strategy consist to [516]:

- It works at low applied potential, allowing a significant decrease of the risk of electrochemical interferences;

- The antioxidant capacity evaluation, requiring the monitoring of $\mathrm{H}_{2} \mathrm{O}_{2}$ concentration in presence of antioxidant sample as well as in its absence, will be a global estimation of the free radicals $\left(\mathrm{O}_{2}^{-}\right)$and nonradical reactive species, $\left(\mathrm{H}_{2} \mathrm{O}_{2}\right)$ interactions with the investigated ontioxidant (AOX) (Reaction 1).

\section{Experimental}

\section{Synthesis of some benzamides derivatives}

Access to these amides requires the preparation of the acid chloride from salicylic acid by the action of thionyl chloride followed by nucleophilic attack of arylamines (Scheme 1). The different molecules
(A, B and C) shown in Scheme 2, are obtained and purified by chromatography on silica gel and characterized by ${ }^{1} \mathrm{H}$ and ${ }^{13} \mathrm{C}$ NMR spectroscopy.

Experimental section: Melting points were taking for samples in capillary tubes with an electro-thermal apparatus and are uncorrected. ${ }^{1} \mathrm{H}$ NMR and ${ }^{13} \mathrm{C}$ NMR were recorded on a Bruker Avance DPX250 spectrometre (300 MHz 1H, $75 \mathrm{MHz} 13 \mathrm{C})$ using trimethylsilane as the internal standard, chemical shifts were reported in parts per million (ppm, $\delta$ units). Coupling constants were reported in units of hertz $(\mathrm{Hz})$. Flash chromatography was performed on silica gel 60 (40-63 mesh). Thin layer chromatography (TLC) was carried out on Merck silica gel

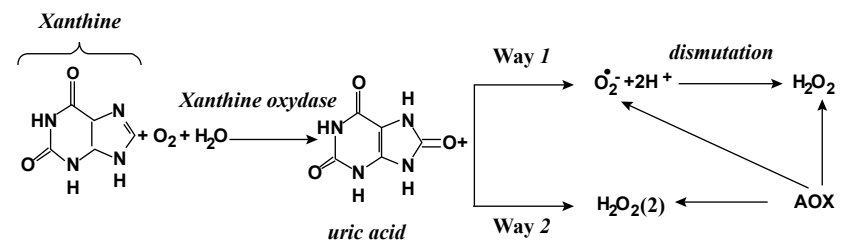

Reaction 1: Synthesis of benzamide from xanthine to xanthine oxidase.



Scheme 1: Synthesis of benzamidederivatives.

*Corresponding author: Abdelilah Chtaini, Equipe of Molecular Electrochemistry and Inorganic Materials, Sultan Moulay Slimane University, Faculty of Science and Technology of Beni Mellal, Morocco, Tel: +212523485112; Fax: +212523485201; E-mail: a.chtaini@usms.ma

Received April 11, 2014; Accepted April 28, 2014; Published April 30, 2014

Citation: Lauriane NTR, Bouali J, Najih R, Khouili M, Hafid A, et al. (2014) Synthesis and Electrochemical Evaluation of Some Organic Molecules as an Antioxidant Agents. Pharm Anal Acta 5: 296. doi:10.4172/2153-2435.1000296

Copyright: ( 2014 Lauriane NTR, et al. This is an open-access article distributed under the terms of the Creative Commons Attribution License, which permits unrestricted use, distribution, and reproduction in any medium, provided the original author and source are credited. 


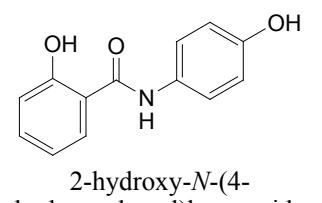

hydroxyphenyl)benzamide Molecule $\underline{A}$
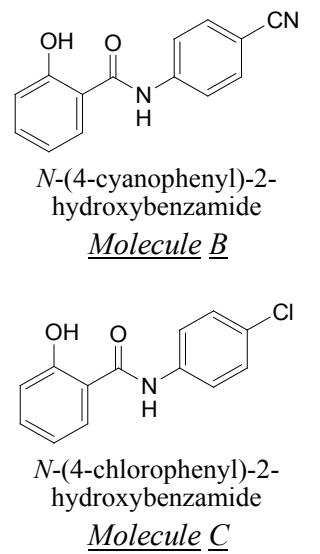

Scheme 2: The differentmolecules (A, B and C) obtained from benzamide derivatives, purified by chromatography on silica gel.

60F254 precoated plates. Visualization was made with ultraviolet light. All organic solvents were distilled immediately prior to use.

General procedure for the synthesis of compounds A, B and C: Salicylic acid ( $2 \mathrm{~g}, 0.013 \mathrm{~mol})$ was dissolved in thionyl chloride $(16.07 \mathrm{~g}, 0.13 \mathrm{~mol})$. The mixture was stirred at reflux for 2 hours. After evaporation of the $\mathrm{SOCl}_{2}$, the residue obtained is dissolved in $\mathrm{CH}_{2} \mathrm{Cl}_{2}$ $(20 \mathrm{~mL})$ and phenylhydrazine $(1.75 \mathrm{~g}, 0.016 \mathrm{~mol})$ and triethylamine $(1.36 \mathrm{~g}, 0.013 \mathrm{~mol})$ were added. The reaction mixture is stirred at room temperature for 5 hours. After hydrolysis with a solution of $\mathrm{NaOH}$ $(1 \mathrm{~N})$, the mixture was extracted with $\mathrm{CH}_{2} \mathrm{Cl}_{2}$. The organic phases are combined, dried over $\mathrm{MgSO}_{4}$, filtered and evaporated under reduced pressure. The crude product thus obtained was purified by silica gel chromatography (eluent: ethyl acetate/hexane: 4/6) leading to the desired compound in good yield.

2-hydroxy- $\mathrm{N}$-(4-hydroxyphenyl)benzamide A: This compound was obtained as a white solid (70\%). Mp: $155-157^{\circ} \mathrm{C} .{ }^{1} \mathrm{H}$ NMR $(300$ MHz, DMSO) d 11.75 (s, 1H, NH), 10.45 (s, 1H, OH), 10.27 (s, 1H, $\mathrm{OH}), 7.78(\mathrm{~d}, J=8,7 \mathrm{~Hz}, 2 \mathrm{H}, \mathrm{ArH}), 7.30(\mathrm{~d}, J=8,7 \mathrm{~Hz}, 2 \mathrm{H}, \mathrm{ArH}), 7.10$ $6.95(\mathrm{~m}, 2 \mathrm{H}, \mathrm{ArH}), 6.85(\mathrm{t}, J=16,8 \mathrm{~Hz}, 1 \mathrm{H}, \mathrm{ArH}), 7.50(\mathrm{t}, J=13,6 \mathrm{~Hz}, 1 \mathrm{H}$, ArH); ${ }^{13} \mathrm{C}$ NMR (75 MHz, DMSO): d 167.8, 159.4, 154.1, 137.2, 131.8, $123.1,121.5,120.1,118.1,118.0$.

$\mathrm{N}$-(4-cyanophenyl)-2-hydroxybenzamide B: This compound was obtained as a (marron Claire) solid (73\%). Mp: $164-166^{\circ} \mathrm{C} .{ }^{1} \mathrm{H}$ NMR (300 MHz, DMSO) d 11.41 (s, 1H, NH), 10.70 (s, 1H, OH), 6.9-79 (m, $8 \mathrm{H}, \mathrm{ArH}) ;{ }^{13} \mathrm{C}$ NMR (75 MHz, DMSO): d 164.8, 159.4, 140.2, 133.6, $132.4,128.9,122.3,121.5,119.9,116.0,115.8,108.2$.

N-(4-chlorophenyl)-2-hydroxybenzamide C: This compound was obtained as a white solid (67\%). Mp: $185-187^{\circ} \mathrm{C} .1 \mathrm{H} \mathrm{NMR}(300 \mathrm{MHz}$, DMSO) d 11.58 (s, 1H, NH), 10.13 (s, 1H, OH), 6.9-8.2 (m, 8H, ArH); 13C NMR (75 MHz, DMSO): d 164.8, 159.4, 134.0, 133.6, 129.9, 129.1, $128.9,123.0,121.5,119.9,116.0$.

\section{Apparatus}

Electrochemical experiments were performed using a voltalab potentiostat (model PGSTAT 100, Eco Chemie B. V., Utrecht, The Netherlands) driven by the general purpose electrochemical systems data processing software (voltalab master 4 software).

All the electrochemical experiments were performed in a standard one-compartment three-electrode cell. The reference electrode was SCE and the counter electrode was platinum. All electrode potentials were referred to this reference electrode. The working electrode was copper modified carbon paste electrode ( $\mathrm{Cu}-\mathrm{CPE})$.

\section{Reagents and solutions}

All chemicals were of the highest quality. Graphite powder (spectroscopic grade RWB, Ringsdorff-Werke GmbH, Bonn-Bad Godesberg, Germany) was obtained from Aldrich and was used without further purification. $\mathrm{CuSO}_{4}$ was obtained from Merck chemicals. Deionised water was used to prepare all solution.

\section{Preparation of the electrochemical sensor}

The carbon paste unmodified was prepared by adding paraffin oil to carbon powder and thoroughly hand-mixing in a mortar and pestle. The resulting paste was packed into the electrode and the surface was smoothed. The electrochemical sensor was developed by depositing the copper at fixed potential $(0.1 \mathrm{~V}$ for 1 hour $)$ onto the carbon paste electrode surface.

\section{Procedure}

The device constructed for the measurement of the antioxidant capacity is given in Figure 1. The free radical was generated in column following the reaction 1 and the graph plot, giving reduction $\mathrm{H}_{2} \mathrm{O}_{2}$ current density versus $\left[\mathrm{H}_{2} \mathrm{O}_{2}\right]$, was carried out. In the second time, the investigated antioxidant associated to xanthine solution were pouring in column and response behaviour was recorded.

\section{Results and Discussion}

\section{Electrochemical behaviour of the studied molecules}

The cyclic voltammograms (CVs) recorded at $\mathrm{Cu}-\mathrm{CPE}$ in the supporting electrolyte containing or not molecule are presented in Figure 2. In presence of molecule A in medium, we note, higher current densities of the anodic side and the occurrence of a reduction peak in the cathodic scanning.

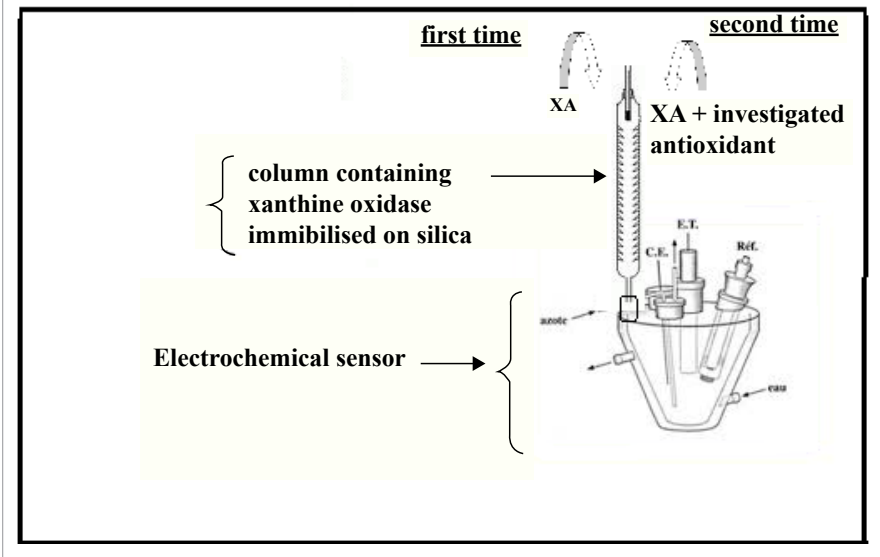

Figure 1: Scheme of the device constructed for the measurement antioxidant capacity. 
Citation: Lauriane NTR, Bouali J, Najih R, Khouili M, Hafid A, et al. (2014) Synthesis and Electrochemical Evaluation of Some Organic Molecules as an Antioxidant Agents. Pharm Anal Acta 5: 296. doi:10.4172/2153-2435.1000296

Page 3 of 5

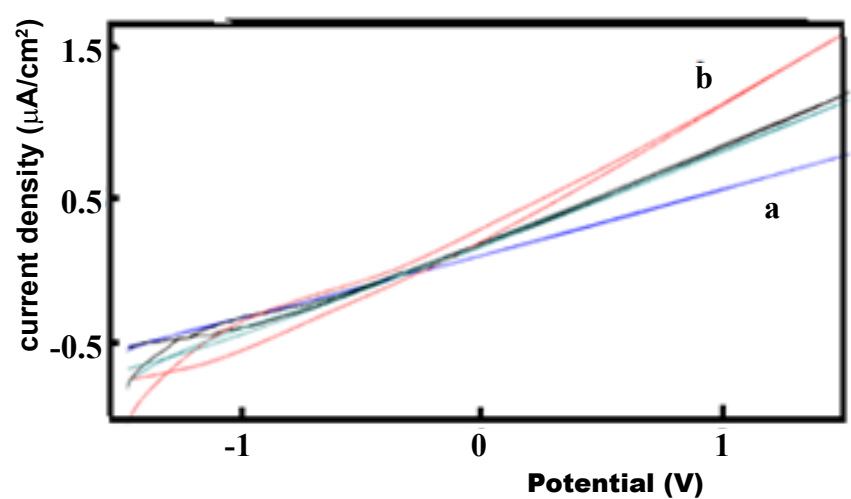

Figure 2: Cyclic voltammograms recorded at Cu-CPE in a-buffer solution b-buffer solution containing molecule $\mathrm{A}$.

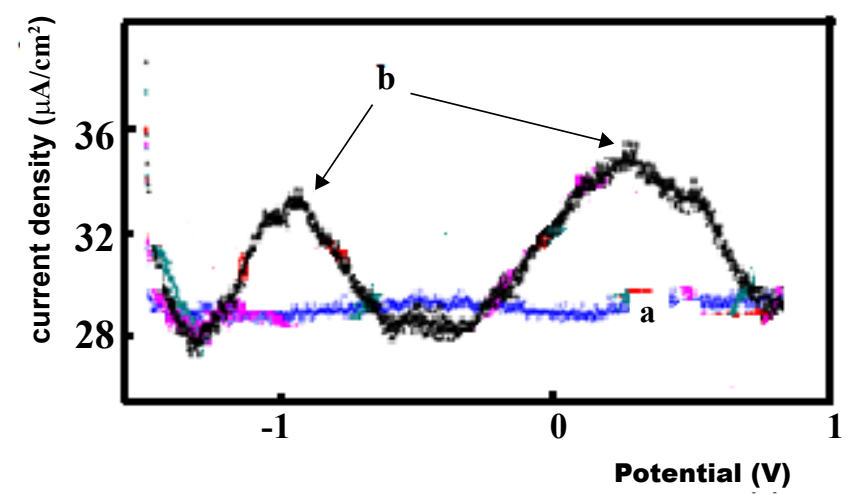

Figure 3: Square wave voltammogram recorded at $\mathrm{Cu}-\mathrm{CPE}$ in, a-buffer solution and b- buffer solution containing molecule $\mathrm{A}$.

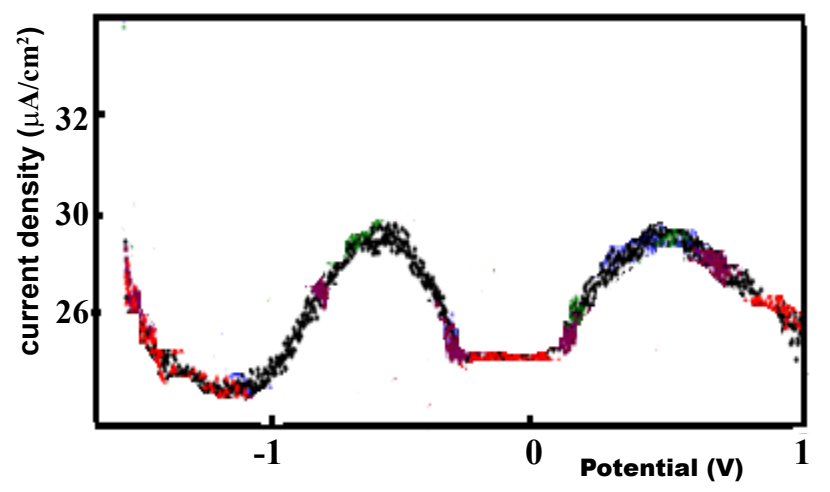

Figure 4: Square wave voltammogram recorded at Cu-CPE in, a-buffer solution and b-buffer solution containing molecule $\mathrm{B}$.

The square wave (SQW) voltammograms obtained, respectively, in buffer solution (curve a) and buffer solution containing molecule A (curve b) are shown in Figure 3. In the presence of the molecule A in the buffer solution causes the appearance of two redox peaks in the SQW voltammogram. The first one around $-1.0 \mathrm{~V}$ and the second at $0.4 \mathrm{~V}$ versus SCE. Peaks can be attributed to redox responses of molecule A.

The same behavior was observed in the presence of the molecule $B$ in the electrolytic solution. The two redox peaks are shifted by about $0.5 \mathrm{~V}$ (Figure 4).
A compared square wave voltammograms corresponding to studied molecules shows that only the molecules $\mathrm{A}$ and $\mathrm{B}$ gives rise to two welldefined redox peaks (Figure 5).

\section{Antioxidant capacity evaluation}

Molecule A: The anti-oxidant properties of the studied molecules were evaluated, investigating square wave voltammetry, by comparing the reduction of $\mathrm{H}_{2} \mathrm{O}_{2}$ in the presence and absence of the considered molecule.

We can see from Figure 6 that, the progressive addition of the solution containing molecule $\mathrm{A}$, leads to the decrease of the $\mathrm{H}_{2} \mathrm{O}_{2}$ reduction current density (in absolute value). The complete inhibition of the reduction reaction of hydrogen peroxide requires $100 \mu \mathrm{L} / 100$ $\mathrm{mL}$ (buffered solution) (Figure 7).

The inhibition of the oxidative capacity of molecule A by $\mathrm{H}_{2} \mathrm{O}_{2}$ was investigated in Figure 8. The hydrogen peroxide formed in the silica column is added, to a phosphate buffer solution containing the molecule $\mathrm{A}$, in the electrochemical cell. We note that the antioxidant molecule A power down depending on the amount of $\mathrm{H}_{2} \mathrm{O}_{2}$ paid.

The same experiments were conducted for molecules B and C. The same behavior is observed (Figures 9 and 10).

\section{Conclusion}

In this work, the antioxidant capacities of three synthesized

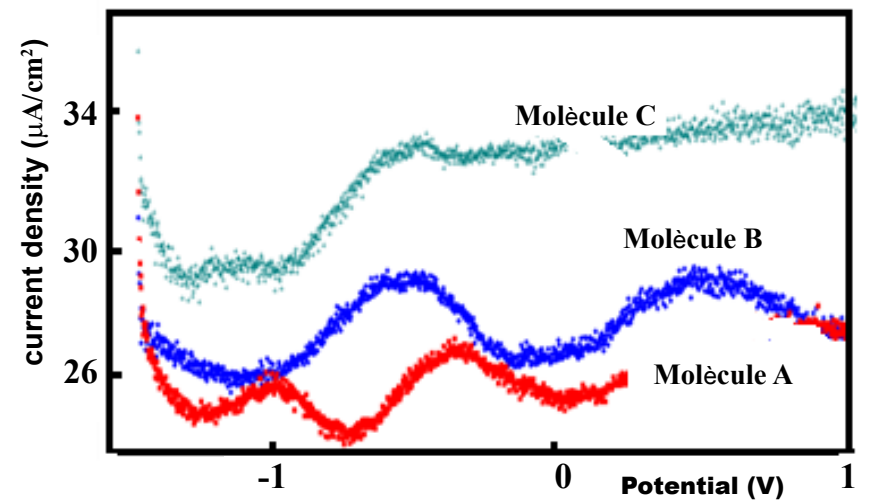

Figure 5: SQW voltammograms recorded in buffer solution containing, respectively, the studied molecule.

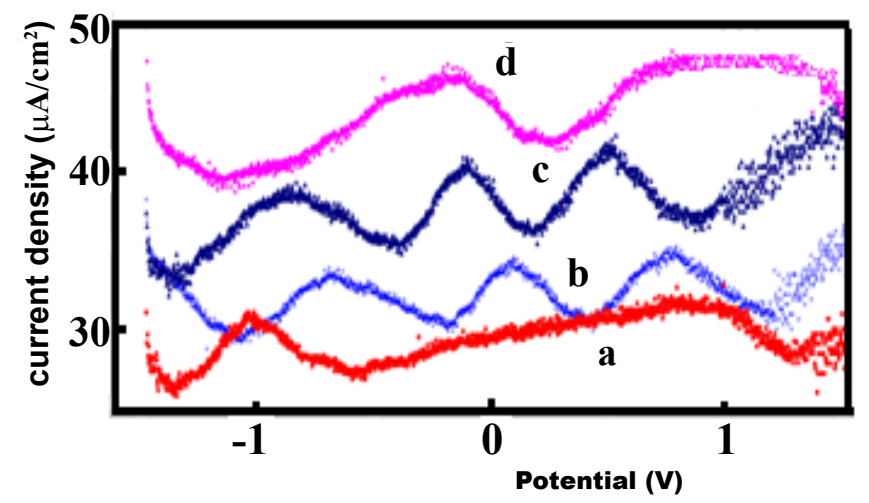

Figure 6: $\mathrm{SQW}$ voltammograms enregistred at $\mathrm{Cu}-\mathrm{CPE}$, in buffer solution containng, d-100 $\mu \mathrm{L}$ of $\mathrm{H}_{2} \mathrm{O}_{2}$, C-addition of $8 \mu \mathrm{L}$ of molécule $\mathrm{A}$, b-addition of $12 \mu \mathrm{L}$ of molecule $\mathrm{A}$ and a- addition of $14 \mu \mathrm{L}$ of molecule $\mathrm{A}$. 
Citation: Lauriane NTR, Bouali J, Najih R, Khouili M, Hafid A, et al. (2014) Synthesis and Electrochemical Evaluation of Some Organic Molecules as an Antioxidant Agents. Pharm Anal Acta 5: 296. doi:10.4172/2153-2435.1000296

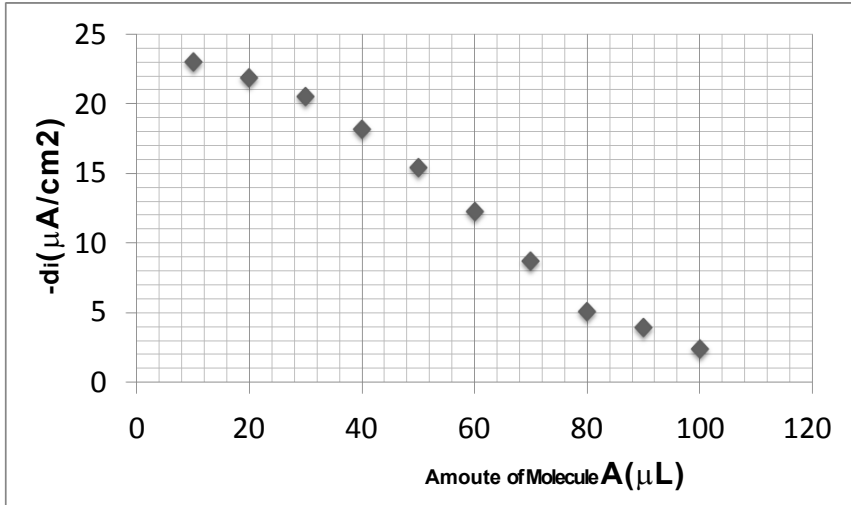

Figure 7: Evolution of the $\mathrm{H}_{2} \mathrm{O}_{2}$ reduction current density with the concentration of molecule $\mathrm{A}$.

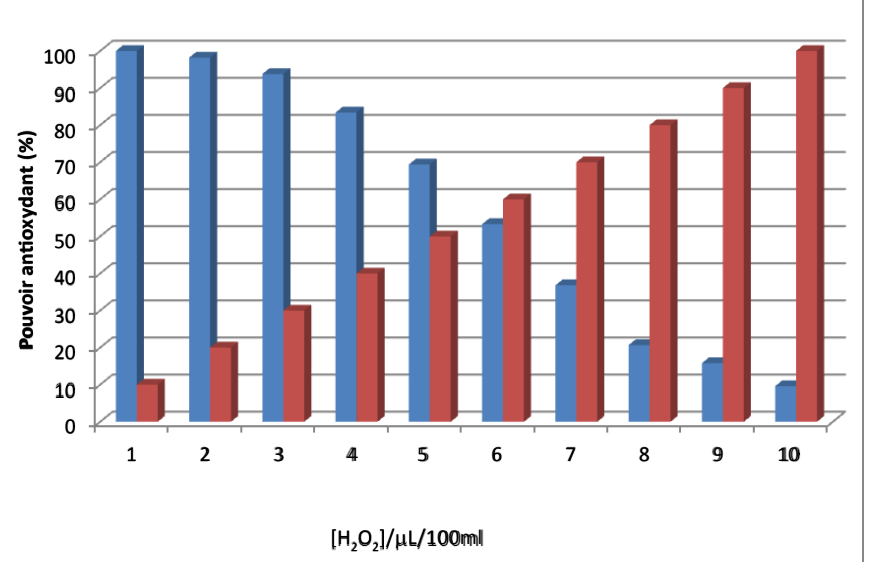

Figure 8: Evolution of antioxidant capacity of molecule A depending on the $\mathrm{H}_{2} \mathrm{O}_{2}$ concentration.

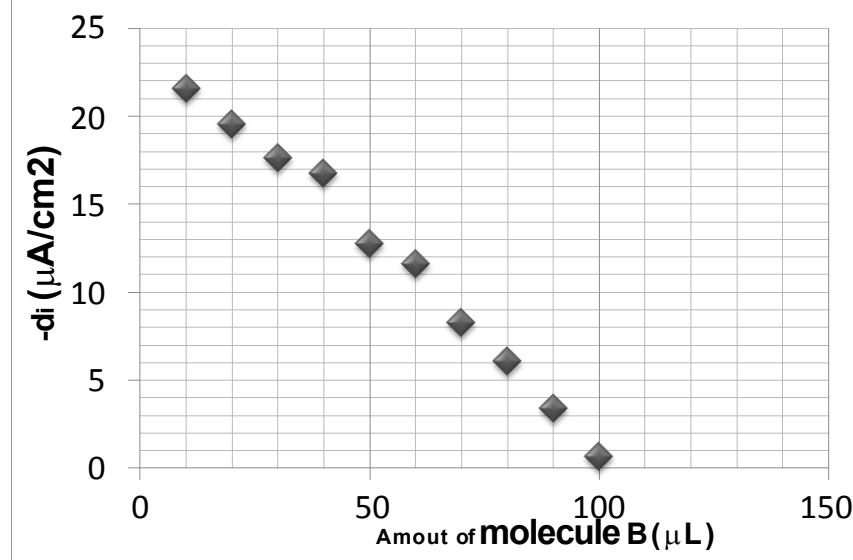

Figure 9: Evolution of the $\mathrm{H}_{2} \mathrm{O}_{2}$ reduction current density with the concentration of molecule $B$.

molecules were investigated based on an electrochemical sensor using copper modified carbon paste electrode as work electrode. The study of SQW voltammograms showed that this sensor had good properties in detection of $\mathrm{H}_{2} \mathrm{O}_{2}$ in electrochemical cell. $\mathrm{H}_{2} \mathrm{O}_{2}$ is generated in silica column based on xanthine/xanthine oxidase system. The experiment procedure exhibited good stability and reproducibility.

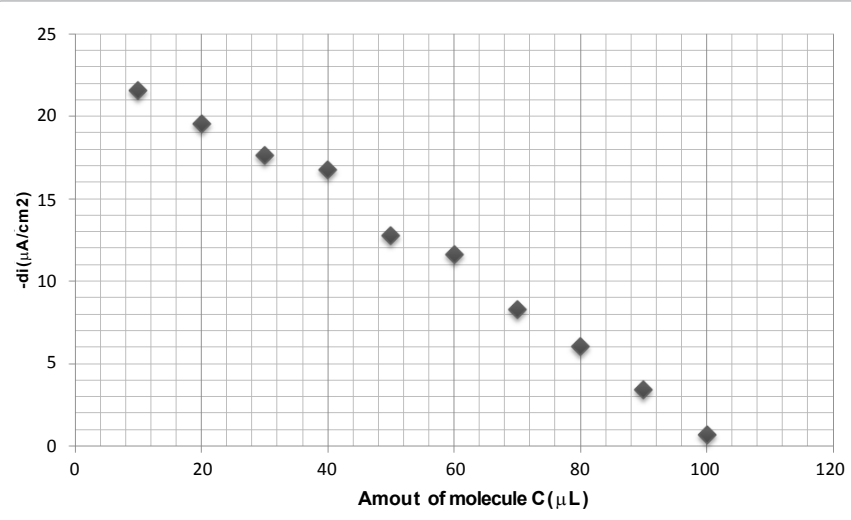

Figure 10: Evolution of the $\mathrm{H}_{2} \mathrm{O}_{2}$ reduction current density with the concentration of molecule $\mathrm{C}$.

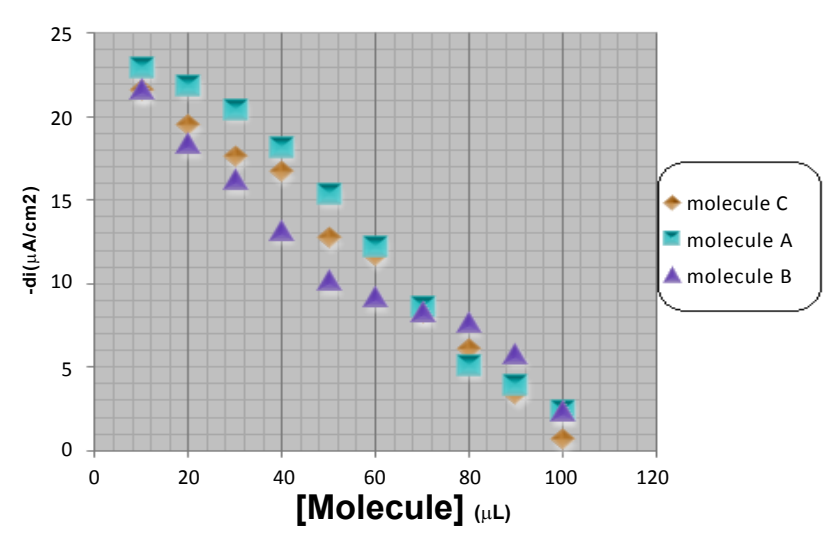

Figure 11: Comparison of Antioxidant capacity of the studied molecules.

Antioxidant capacity (AOC) of the studied molecules varies in the following sense (Figure 11):

\section{- For concentrations $\leq 60 \mu \mathrm{L} / 100 \mathrm{~mL}$}

AOC (molecule B) $\geq$ AOC (molecule C) $\geq$ AOC (molecule A)

- For concentrations $\geq 60 \mu \mathrm{L} / 100 \mathrm{~mL}$

AOC (molecule C) $\geq$ AOC (molecule A) $\geq$ AOC (molecule B)

\section{References}

1. Jeffrey SA, Mahadevan R, Watee C, Paul G, Wayne JH, et al.(1999) Characterization of reactive oxygen species induced effects on human spermatozoa movement and energy metabolism. Free Radical Biology and Medicine 26: 869-880.

2. Liu QJ, Liu HF, Yuan ZI, Wei DW, Ye YZ (2012) Evaluation of antioxidant activity of chrysanthemum extracts and tea beverages by gold nanoparticles-based assay. Colloids and Surfaces B: Biointerfaces 92: 348-352.

3. Bian CL, Xiong HY, Zhang XH, Wen W, Wang SF (2011) An electrochemical biosensor for analysis of Fenton-mediated oxidative damage to BSA using polyo-phenylenediamine as electroactive probe. Biosensors and Bioelectronics 28 : 216-220.

4. Wang X, Jiao Yu CZ (2014) Electrochemical biosensor for assessment of the total antioxidant capacity of orange juice beverage based on the immobilizing DNA on a poly l-glutamic acid doped silver hybridized membrane. Sensors and Actuators B: Chemical 192: 628-633.

5. Mello L, Kubota L (2007) Biosensors as a tool for the antioxidant status evaluation. Talanta 72: 335-348. 
Citation: Lauriane NTR, Bouali J, Najih R, Khouili M, Hafid A, et al. (2014) Synthesis and Electrochemical Evaluation of Some Organic Molecules as an Antioxidant Agents. Pharm Anal Acta 5: 296. doi:10.4172/2153-2435.1000296

Page 5 of 5

6. Campanella L, Bonnani A, Finotti E, Tomassetti M (2004) Biosensors for determination of total and natural antioxidant capacity of red and white wines: comparison with other spectrophotometric and fluorimetric methods. Biosensors and Bioelectronics 19: 641-651.

7. Campanella L, Favero G, Persi L, Tomassetti M (1999) Superoxide Dismutase Biosensors for Superoxide Radical Analysis. Anal Lett 32: 2559-2581.

8. Bonnani A, Campanella AL, Gatta T, Gregoria E, Tomassetti M (2007) Evaluation of the antioxidant and prooxidant properties of several commercial dry spices by different analytical methods. Food Chem 102: 751-758.

9. Campanella L, Bonnani A, Favero G, Tomassetti M (2003) Determination of antioxidant properties of aromatic herbs, olives and fresh fruit using an enzymatic sensor. Analytical and Bioanalytical Chemistry 375: 1011-1016.

10. Di J, Bi S, Zhang M (2004) Surface plasmon resonance immunosensor for the detection of Salmonella typhimurium. BiosensBioelectron 19: 1486-1497.
11. Tiam Y, Okajima T, Kitamura F, Ohsaka T (2002) A SOD-Based Amperometric Biosensor for Superoxide Ion. J Korean Electrochem Soc 5: 212-215.

12. Emregul E (2005) Development of a new biosensor for superoxide radicals Anal Bioanal Chem 383: 947-954.

13. Mesaros S, Vankova Z, Mesarosova A, Tomcik AP, Grufeld S (1998) Electrochemical determination of superoxide and nitric oxide generated from biological samples. Bioelectrochem. Bioenergy 46: 33-37.

14. Ignatov S, Shishniashvili D, Ge B, Scheller F, Lisdat F (2002) Amperometric biosensor based on a functionalized gold electrode for the detection of antioxidants. Biosens Bioelectron 17: 191-199.

15. Lisdat F, Ge B, Rezeka R, Kozniewska E, Fresentius (1999) J Anal Chem 365 494-498.

16. Beissenhirtz M, Scheller F, Lisdat F (2003) Immobilized Cytochrome Sensor in Organic/Aqueous Media for the Characterization of Hydrophilic and Hydrophobic Antioxidants Electroanal 15: 1425-1435. 